\title{
Changes in cutaneous sensitivity after prolonged exposure to unpatterned light
}

\author{
John P. Zubek, J. Flye and D. Willows \\ UNIVERSITY OF MANITOBA, CANADA
}

\begin{abstract}
Abstraet
Ss who were exposed to diffuse, homogeneous illumination for a week showed an increase in tactual acuity and in sensitivity to heat and pain. This cutaneous supersensitivity, however, was not as pronounced as that occurring after a week of darkness.
\end{abstract}

\section{Problem}

Of the various behavioral effects produced by prolonged exposure to sensory and perceptual deprivation, one of the most perplexing is an increase in pain sensitivity (Vernon \& McGill, 1961) and in tactual acuity as measured by both a two-point threshold (Doane et al., 1959) and a tactual fusion method (Zubek, 1964). Recently, Zubek et al. (1964) demonstrated that an overall reduction in the level of visual, auditory, tactualproprioceptive, and social stimulation is not essential for the appearance of this cutaneous supersensitivity. It can occur following visual deprivation alone. In this study, the Ss, who were exposed to a week of darkness, showed a pronounced increase in tactual acuity and in sensitivity to heat and pain. This effect of visual deprivation was uniform. It was shown by all experimental Ss, on all skin areas, and on all cutaneous measures. Furthermore, the effects were still present several days after the termination of darkness.

The purpose of the present study is to determine whether similar effects will result from prolonged exposure to diffuse, homogeneous illumination. If this should occur, it will suggest that these cutaneous effects have resulted from an absence of pattern vision rather than an absence of visual stimulation per se.

\section{Method}

Eighteen male university students were placed, in groups of two or three, in a constantly illuminated room for a prescribed period of one week. Each S wore a pair of translucent goggles which permitted diffuse light but eliminated all pattern vision. The illumination under the goggles was 15-ft candles (below overhead lights with $\mathrm{S}$ in supine position). Apart from the exposure to constant light, their environment was quite normal. No gloves were worn and no restrictions were placed on their motor activity or on conversation with one another. Furthermore, a radio was available in the room at all times.

Measures of tactual acuity were taken from the palm, index finger, and forearm before and immediately after the week of unpatterned light as well as at intervals of $1,2,5$, and 7 days after termination of the experimental condition. The acuity of the palm was determined by the two-point threshold technique. Four trials were given on each palm. The acuity of the index finger and forearm was measured by a fusion method which utilizes an interrupted jet of air at a specified pressure whose frequency can be increased until $\mathrm{S}$ reports a constant sensation of pressure on the skin. This threshold value is referred to as the CFP or critical frequency of percussion. Four experimental trials were given on each index finger and on the volar surface of each forearm, $8 \mathrm{~cm}$ below the elbow. In addition to tactual acuity, measures of heat and pain sensitivity were taken from the forearm, before and after the week of unpatterned light, by the Hardy, Wolff, and Goodell dolorimeter. The basal setting for the instrument was $100 \mathrm{mcal} / \mathrm{cm}^{2} \mathrm{sec}$. for a skin temperature of $34^{\circ} \mathrm{C}$. Ss were asked to indicate when they felt the first sensation of warmth and, subsequently, when they experienced the first sensation of pricking pain. The latency, in seconds, was measured by a Hunter Klockounter and a Standard high speed timer. Four heat and four pain trials were given on each forearm with the trials separated by a 1-min. interval. Practice trials on the various cutaneous measures were given a day prior to the experimental session.

A group of 40 control Ss received the same tests and at the same time intervals as the experimentals but they were never exposed to unpatterned light. For purposes of statistical analysis, the predeprivation scores of the 18 experimental Ss, on the various cutaneous measures, were matched with the initial scores of 18 of the 40 controls. This sample of controls was found to be sufficiently large to produce a good matching with the smaller experimental group. Twotailed t-tests for correlated measures were used in the statistical analysis.

\section{Results}

Figure 1 indicates that the experimental Ss, after a week's exposure to unpatterned light, show an increase in tactual acuity of both the finger and the forearm in relation to that of the matched controls ( $\left.p^{\prime} s<.01\right)$. Furthermore, there are suggestions that this effect persists for several days after the termination of the experimental condition. However, for the finger, only the "post day 1 " difference between conditions is significant $(p<.05)$; for the forearm, none of the posttreatment differences are statistically significant. Figure 2 indicates a slight improvement in the tactual acuity of the palm after exposure to unpatterned light.

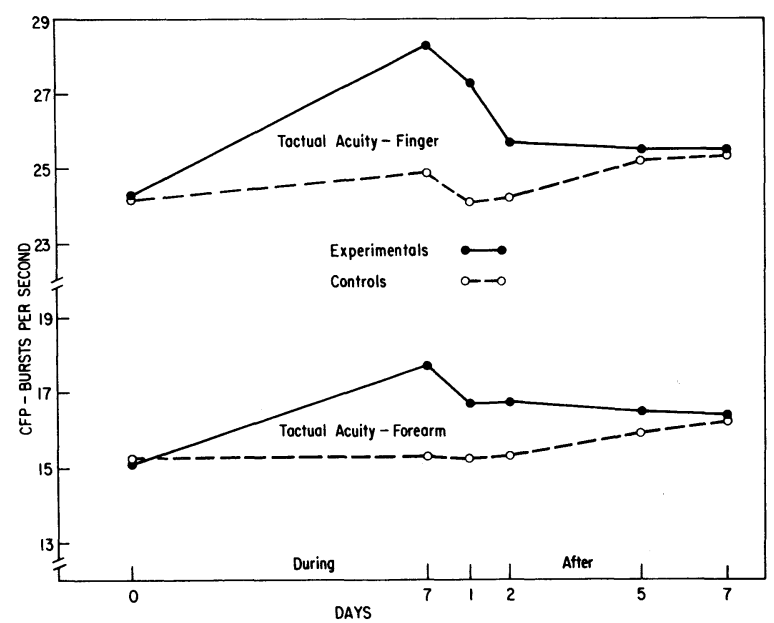

Fig. 1. Tactual acuity of the index finger and forearm, as measured by a fusion method, before and after a week of homogeneous illumination, and $1,2,5$, and 7 days later. 
This change, however, is not statistically significant. This discrepancy in results between the palm and the finger and forearm may simply be due to the fact that the two-point threshold, taken on the palm, is not a sufficiently sensitive measure to detect the phenomenon. Finally, Fig. 3 shows an increase in sensitivity to both pain $(p<.001)$ and heat $(p<.01)$. Furthermore, this supersensitivity still persists on "post day 2 " for heat $(p<.05)$ and "post day 1 " for pain $(p<.05)$.

An examination of the individual performance of the 18 experimental Ss revealed that the post-deprivation changes were, in general, quite uniform. Increased sensitivity to heat and pain was shown by 16 of the 18 Ss while increased finger and forearm acuity was present in 14 and $16 \mathrm{Ss}$, respectively. On the otherhand, an improved two-point threshold of the palm was only shown by 10 of the $18 \mathrm{Ss}$, a chance performance.

\section{Diseus sion}

This study indicates that cutaneous supersensitivity can be produced not only by darkness but also by prolonged exposure to homogeneous illumination. This similarity seems to suggest that it is the absence of pattern vision or of $\mathrm{changes}$ in visual input rather than absence of visual stimulation per se which is responsible for the increased cutaneous sensitivity. Although the effects of diffuse light and darkness are similar, they are not identical. For example, the increase in finger and forearm acuity and the duration of the aftereffect is not as great after unpatterned light

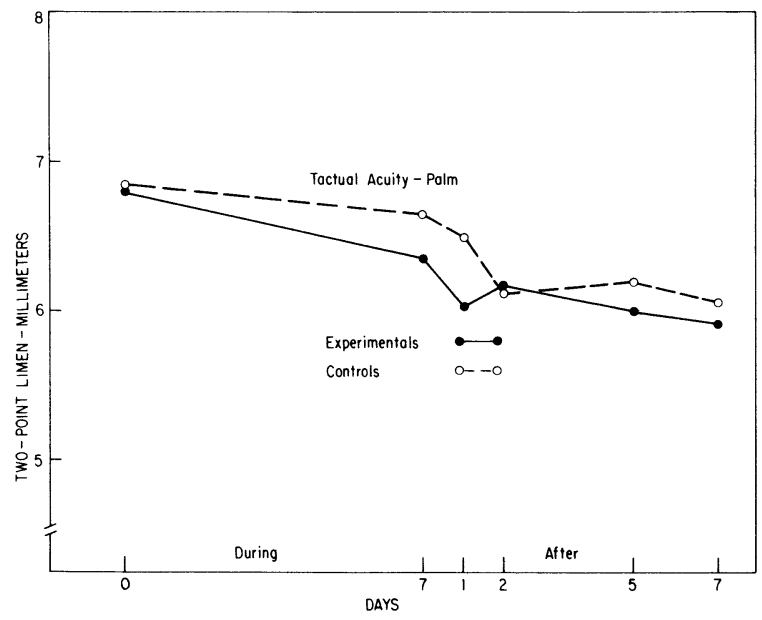

Fig. 2. Tactual acuity of the palm, as measured by a two-point threshold method, before and after a week of homogeneous illumination, and $1,2,5$, and 7 days later.

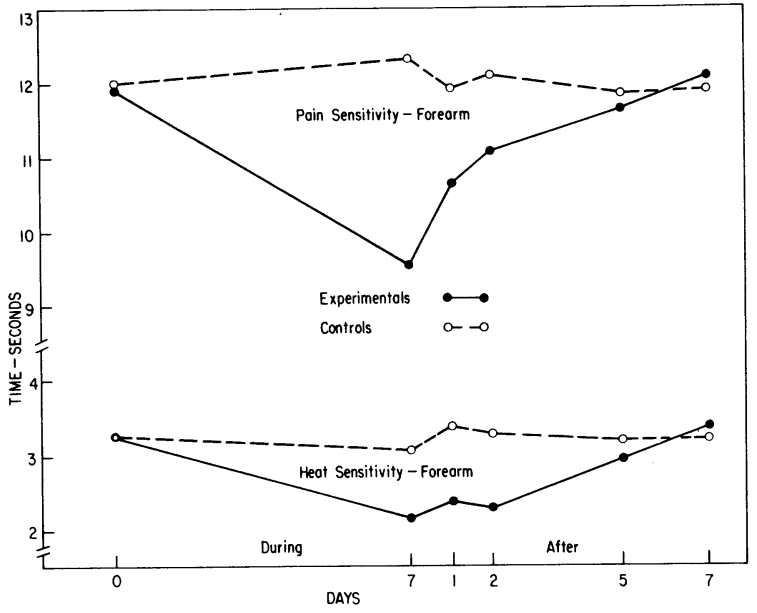

Fig. 3. Heat and pain sensitivity of the forearm, before and after a week of homogeneous illumination, and 1 , 2,5 , and 7 days later.

as after darkness. Likewise, the two-point threshold of the palm shows little evidence of improvement whereas, after darkness, the effect is pronounced. One possible explanation of this differential effect may be the presence, during unpatterned light, of random fluctuations in level of illumination resulting from the opening and closing of the eyes together with movements of the head away from the overhead light source. During darkness this would not be a factor. However, during exposure to diffuse light these random variations in illumination may serve to "alert" the neurovisual system periodically and hence diminish the magnitude of the cutaneous effects.

These cutaneous effects are believed to have resulted from changes in the excitability of the cerebral cortex. The physiological evidence supporting this hypothesis has been presented in our earlier paper.

\section{References}

DOANE, B. K., MAHATOO, W., HERON, W., \& SCOTT, T. H. Changes in perceptual function after isolation. Canad. J. Psychol., 1959, 13, 210-219.

VERNON, J., \& MCGILL, T. E. Sensory deprivation and pain thresholds. Science, 1961, 133, 330-331.

ZUBEK, J. P. Behavioral changes after prolonged perceptual deprivation (no intrusions). Percept. mot. Skills, 1964, 18, 413-420.

ZUBEK, J. P., FLYE, J., \& AFTANAS, M. Cutaneous sensitivity after prolonged visual deprivation. Science, 1964, 144, 1591-1593.

Note

1. This research was supported by the Defence Research Board, Canada (No. 9425-08) and by the National Research Council, Canada (APT-106). The authors wish to express their appreciation to Miss C. Chapman and Mr. P. Duda for experimental assistance. 